\title{
ANOMALOUS PULMONARY VENOUS DRAINAGE
}

\author{
BY \\ JOHN B. HICKIE, ${ }^{*}$ T. M. D. GIMLETTE, AND A. P. C. BACON \\ From the Cardiac Department, St. Thomas' Hospital
}

Received September 4, 1955

The diagnosis of anomalous pulmonary venous drainage has been made with increasing frequency in recent years (Friedlich et al., 1950 ; Swan et al., 1953; Johnson, 1955; Sepulveda et al., 1955), largely due to the use of cardiac catheterization, and has become more important now that the surgical repair of atrial septal defects is possible. The co-existence of these two anomalies is more frequent than has been realized.

Anomalous pulmonary venous drainage was originally described by Winslow (1739) and isolated cases were reported in increasing numbers during the next two centuries. However, these were regarded at the time as little more than interesting anatomical curiosities. Brody (1942) was able to collect 100 reported cases; of these, 36 per cent had complete, and 64 per cent partial anomalous drainage, and among the latter, the right lung was involved in two-thirds of the cases, and an atrial septal defect was present in over half of those about which there was definite information. Instances were described in which the pulmonary veins were connected, in different cases, to all the great veins within the chest and to the portal vein and ductus venosus, but connection was most common with the superior vena cava or the right atrium. Healey (1952) reviewed reports of 155 cases, of which 40 per cent were of total anomalous drainage and, describing 5 cases from a total of 800 anatomical dissections made by himself and others, suggested that anomalous pulmonary veins are not rare in comparison with other congenital cardiovascular abnormalities.

Anomalous veins from the right lung drain most commonly into the superior vena cava or right atrium and are frequently associated with an atrial septal defect. The latter is usually of limited size and is located posteriorly in close proximity to the mouths of the anomalous veins. However, when one or both of the left pulmonary veins drain into the systemic venous system, they usually do so by way of a left superior vena cava or directly into the coronary sinus. Anomalous veins from the right lung often occur without associated anomalous veins from the left lung, but the reverse is unusual and left-sided anomalous pulmonary veins generally occur with complete transposition of all the pulmonary veins and an atrial septal defect.

In our patients right anomalous veins were present in twelve and left in two (in one patient a single left anomalous vein was present); there was no case of the complete anomaly, probably because none of our patients was under 10 years of age; an atrial septal defect was present in nine and possibly in two more; a left superior vena cava in three; pulmonary stenosis in one; mitral stenosis in two, and an abnormality of the Eustachian valve in one (Hickie, 1955).

\section{EMBRYOLOGY}

A brief consideration of the development of the pulmonary veins and interatrial septum will show how anomalous pulmonary veins come to be formed.

In the embryo the lungs develop from the lung bud which forms on the ventral aspect of the foregut, the venous drainage of the lung bud being to the cranial part of the splanchnic plexus surrounding the

* Saltwell Research Scholar, Royal College of Physicians. 
foregut (Fig. 1) (Edwards, 1953; Smith, 1951; Brown, 1913). This plexus is in connection with the sinus venosus and with a number of primitive venous channels in the neighbourhood. As development continues, that part of the venous plexus draining the lung bud forms a single common pulmonary vein, and this comes to enter the sino-atrial chamber by fusion with an outgrowth from the sino-atrial chamber which develops at the same time (Flint, 1906; Squier, 1916; Brantigan, 1947; Edwards, 1953; Buell, 1922; Chang, 1931).

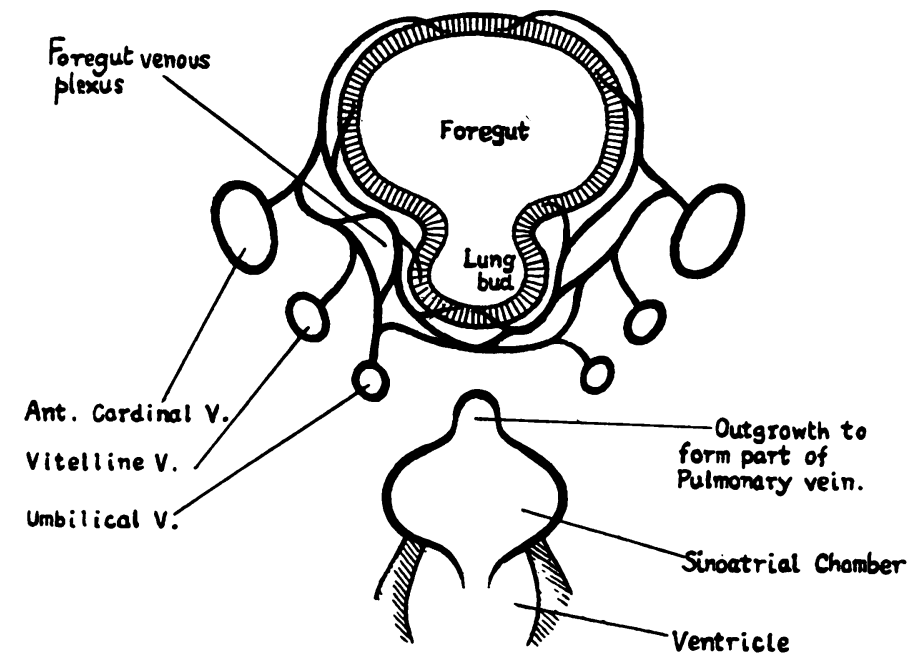

Fig. 1.-Development of lungs and pulmonary veins.

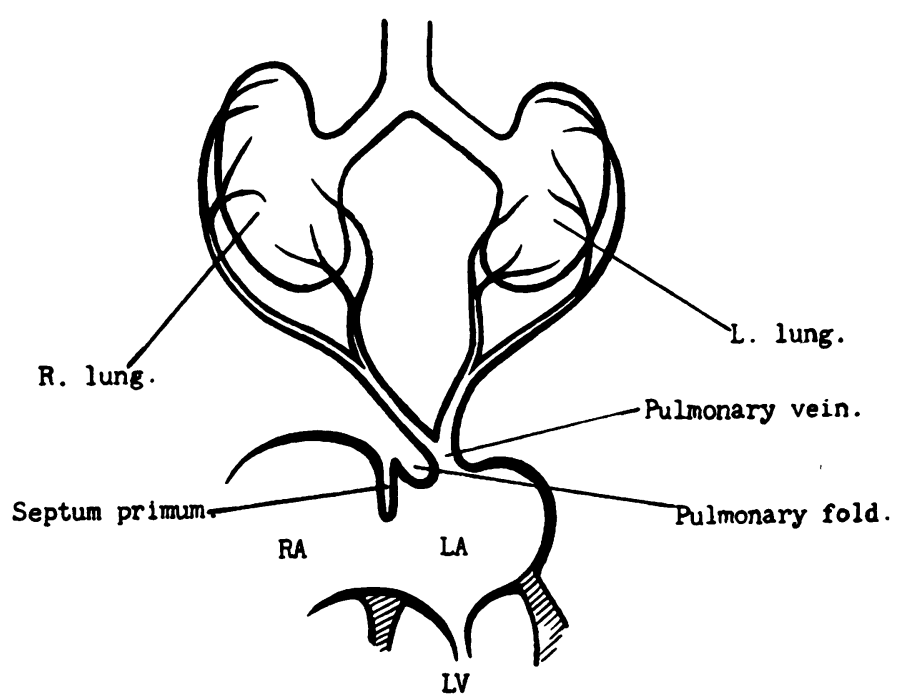

FIG. 2.-Further development of lungs and pulmonary veins.

Later this common pulmonary vein is absorbed into the atrium so that its four branches come to enter the atrium separately; occasionally, however, the common pulmonary vein fails to be absorbed and persists as a supernumary left atrium (Edwards et al., 1951).

The right wall of the newly formed pulmonary vein becomes invaginated into the atrium and forms the pulmonary fold; this separates the opening of the vein from the site of the developing septum primum and leads the pulmonary vein into the left side of the atrial wall clear of the septum. As a result of this process the part of the posterior atrial wall between the septum and the entry of the pulmonary vein is derived from the vein itself (Davies et al., 1937) (Fig. 2). During development of the pulmonary veins there may be failure 
of the common pulmonary vein to connect with the outgrowth from the atrium (Edwards et al., 1951) or failure of the common pulmonary vein to form; either state of affairs will result in some of the connections of the pulmonary venous plexus with the rest of the foregut plexus persisting as the route of venous drainage from the lungs (Edwards, 1953; Brody, 1942). Thus the venous drainage of the lungs may be to any of the venous channels with which the splanchnic plexus of the foregut is connected in early development, including the sinus venosus which becomes part of the right atrium. Fig. 3 illustrates the numerous veins with which

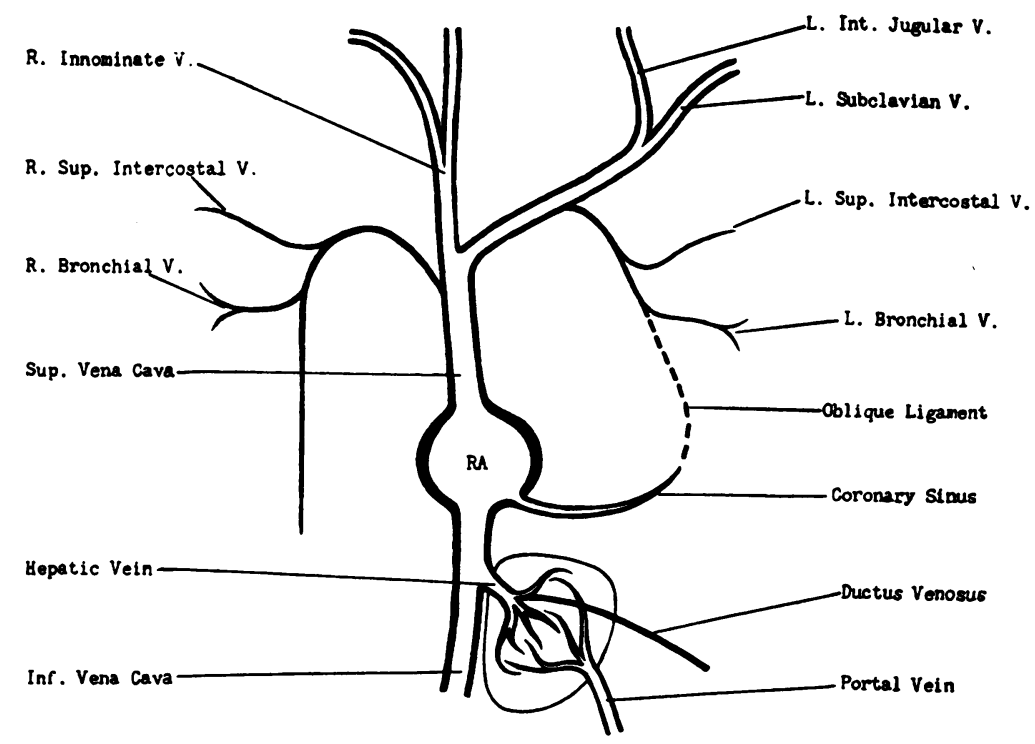

FIG. 3.-This illustrates the numerous veins with which the pulmonary veins may theoretically connect, and with which their connection has been recorded.

the pulmonary veins may theoretically connect, and with which their connection has been recorded (Brantigan, 1947; Healey, 1952) and explains how occasional cases arise where the pulmonary veins connect with such apparently unlikely veins as the portal vein or ductus venosus. It has been suggested that the bronchial veins take over the venous drainage of the lungs when the pulmonary veins fail to form (Conn et al., 1942), but the fact that the bronchial veins normally drain to the azygos and left superior intercostal veins render it unlikely that many of the anomalous pulmonary veins encountered could be enlarged bronchial veins (Edwards et al., 1951; Butler, 1952).

A further explanation of some cases of anomalous connection of the pulmonary veins with the right atrium is that there may be an abnormality in the mode of formation and site of the posterior part of the interatrial septum, so that the pulmonary veins come to enter the atrium partly or wholly on the wrong side of the septum. Failure to form the pulmonary fold is likely to result in the pulmonary veins entering the atrium either to the right of, or occasionally astride, the septum primum; the latter results in a high posterior atrial septal defect with some pulmonary veins entering on one side of the septum, and some on the other (Atkinson et al., 1940).

\section{Physiology}

The fundamental disturbance in anomalous pulmonary veins is similar to that found in an atrial septal defect, namely recirculation of oxygenated blood through the lungs. This increased pulmonary flow causes enlargement of the right atrium, right ventricle, and pulmonary artery and may in time cause raised pulmonary arterial and right ventricular pressures. Symptoms probably do not arise unless the anomalous drainage involves at least the whole of one lung (50 per cent or more of the pulmonary flow) or is associated with an atrial septal defect or is part of a more complicated anomaly (Brody, 1942). Single anomalous veins are usually asymptomatic (Mankin et al., 1953; Dotter et al., 1949). 


\section{Clinical Features}

Clinically it is impossible to differentiate anomalous pulmonary veins and atrial septal defect (Knutson et al., 1950; Mankin et al., 1953; and Johnson, 1955), and as already stressed the two conditions are frequently associated. Complete anomalous pulmonary venous drainage is said to be rare but it was present in 36 per cent of Brody's (1942) series. It is inevitably associated with a patent foramen ovale, an atrial septal defect, a patent ductus arteriosus or a more complicated anomaly. Most cases die in infancy or under six months of age but Snellen et al. (1952); Whitaker et al. (1954); Bruce et al. (1954); and Sepulveda et al. (1955) report patients reaching adult life: three of the latter's six patients had the complete defect, the oldest being aged 42 years. Exertional dyspnœa is usually the predominant symptom. There is no diagnostic murmur but occasionally a venous hum may be found over the left upper chest (Keith et al., 1954).

Our experience is limited to 13 patients with incomplete pulmonary venous drainage. The diagnosis was confirmed at operation (Table I) or autopsy in nine. The sex incidence was equal. The symptoms included progressive dyspnœa (13), recurrent bronchitis (7), hæmoptysis (3), præcordial pain (3), exertional giddiness (3), and palpitation (1). The majority of the patients were asymptomatic for many years. Cardiac failure occurred most often in middle age and was usually rapid in onset. The clinical severity of disability in our patients could not be correlated with either the size of the shunt or with the pulmonary arterial pressure and probably depends largely on the state of the myocardium.

Central cyanosis was a feature in 50 per cent of cases. Otherwise the signs were those of increased pulmonary blood flow, namely a palpable pulmonary arterial and right ventricular impulse or præcordial prominence, a pulmonary systolic murmur (10), a pulmonary diastolic murmur (4), a pulmonary systolic click (4), and an accentuated split pulmonary second sound (9). Mitral murmurs (systolic and/or diastolic) were present in five patients but in only one of these was mitral stenosis present at operation or autopsy. In two patients there were no murmurs and in three the murmurs were most unimpressive.

The jugular venous pressure was raised in nine patients but was associated with a palpable liver and slight ankle œdema in only three and in none was gross right heart failure present. In Case 2 the jugular venous pressure was raised on the right side of the neck and appeared normal on the left and at thoracotomy an aneurysm of the superior vena cava was found.

\section{ELECTROCARDIOGRAPHY}

The electrocardiographic findings in the present series are similar to those in previous reports of atrial septal defect (Bedford et al., 1941; Routier et al., 1940; Barber et al., 1950) and anomalous pulmonary venous drainage (Whitaker, 1954; Geraci, 1953; and Grishman et al., 1945), and it is impossible to distinguish between the two different types of lesion in this way: in view of their similar effects on the circulation this is not surprising, especially as both may be present.

Eleven of our patients were in normal rhythm, one had auricular flutter, and one auricular fibrillation. It is well known that atrial septal defect is the only congenital heart lesion commonly associated with fibrillation, possibly because there may be mitral stenosis also, and in Bedford, Papp, and Parkinson's series (1941) of 53 cases of atrial septal defect, five of the six with auricular fibrillation had mitral stenosis. Their sixth case was fifty-eight years of age, and they stated that they knew of no reported case of auricular fibrillation in isolated atrial septal defect under fifty years of age. Our Case 9, however, had auricular fibrillation and though there was no operative proof, the low pulmonary capillary pressure and slight rise on exercise render it unlikely that she suffered from mitral stenosis.

$P$ waves were normal in seven of the ten cases in normal rhythm, while in three others they were bifid or abnormally peaked in one or more leads. Bifid $\mathrm{P}$ waves in this type of lesion do not necessarily indicate mitral stenosis, and peaked or bifid $\mathrm{P}$ waves may be found in the same subject in different leads (Bedford et al., 1941 ; Brown, 1950). 
The $\mathrm{P}-\mathrm{R}$ interval was increased to more than $0 \cdot 2 \mathrm{sec}$. in only one case.

In no case was the QRS complex completely normal. Complete right bundle-branch block occurred only once, incomplete bundle-branch block four times, and what may be described as right ventricular hypertrophy eight times. The latter term is taken to indicate an RSR pattern in V1 and V4R with deep S waves in V3-V6 but where the duration of the QRS does not exceed $0 \cdot 1$ sec. Grishman et al. (1949) describe three cases of anomalous drainage of the right lower lobe with associated atrial septal defect, and all showed incomplete right bundle-branch block. Six cases of total anomalous pulmonary venous drainage through a persistent left superior vena cava, with associated atrial septal defect, are reported by Whitaker (1954), and while three of the four children under the age of ten showed the pattern of right ventricular hypertrophy, the two adults showed incomplete right bundle-branch block. Brown (1950), referring to isolated atrial septal defect, states that incomplete is commoner then complete right bundle-branch block, and the view that the block is not a congenital abnormality but is induced by progressive right ventricular enlargement is supported by other authors (Bedford et al., 1941; Routier et al., 1940; Wood, 1950). Taussig (1947) and Sepulveda et al. (1955) state that the electrocardiogram may be normal in partial anomalous venous drainage and it seems that the abnormalities are related to the size and duration of the left-to-right shunt. When there is the double pathology there will be a greater left-to-right shunt of blood and right ventricular enlargement, and, therefore, the electrical pattern of right ventricular hypertorphy or bundle-branch block.

\section{X-RAY FINDINGS}

Radiological findings vary according to the site and origin of the anomalous veins, the vessels into which they drain, and the secondary effects that this re-circulation of blood in the pulmonary circuit has upon the size and shape of the heart. Whether or not there is an associated atrial septal defect there is a continuous left-to-right shunt of blood, the effect of this being to cause right ventricular hypertrophy, dilatation of the pulmonary artery and its branches, and congested lung fields; the aorta is usually small. The cardiac outline is of little or no value, therefore, in differentiating this condition from other lesions that cause a left-to-right shunt.

Turning to the shadows formed by the anomalous veins themselves, two characteristic pictures are found.

(1) When the veins from the left and possibly the right lungs, enter a persistent left superior vena cava draining into the left innominate vein, the abnormal vessel may be seen to the left of the upper mediastinum as a homogeneous bulge, which may be seen on fluoroscopy to pulsate. As a consequence of the increased blood flow into the normal superior vena cava, this in turn dilates, may also pulsate, and the abnormal vascular shadows in the superior mediastinum together with the heart form the characteristic " figure of eight" described by Snellen and Albers (1952) and Gardner and Oram (1953). Our Case 2 showed a dilated and pulsating normal right superior vena cava due to anomalous drainage from the right upper lobe. This was the only instance in our 13 cases of any such radiological abnormality and it disappeared following operation (Fig. 4).

(2) Where there is anomalous drainage into the superior or inferior vena cava the aberrant vessel itself may be seen in the conventional chest film. Many authors (Bruwer, 1953; Snellen et al., 1952; and Sepulveda et al., 1955) describe a comma-shaped shadow parallel to and either inside or outside the border of the heart, which disappears from view at the right cardio-phrenic angle where it joins the inferior vena cava. Grishman et al. (1949) point out that these shadows have the homogeneous appearance of a vascular structure, and there is no demonstrable disturbance in the lung fields such as collapse, infiltration, etc. Tomography may sometimes yield further information and in addition to showing the aberrant vessels more clearly it may demonstrate other abnormalities which may co-exist such as bronchial hypogenesis.

Angiocardiography was not employed in any of our cases, although Snellen and Albers (1952) obtained useful information by this method concerning the number of anomalous vessels and their connections. Sepulveda et al (1955) employed angiocardiography in all their cases and emphasize 2B 


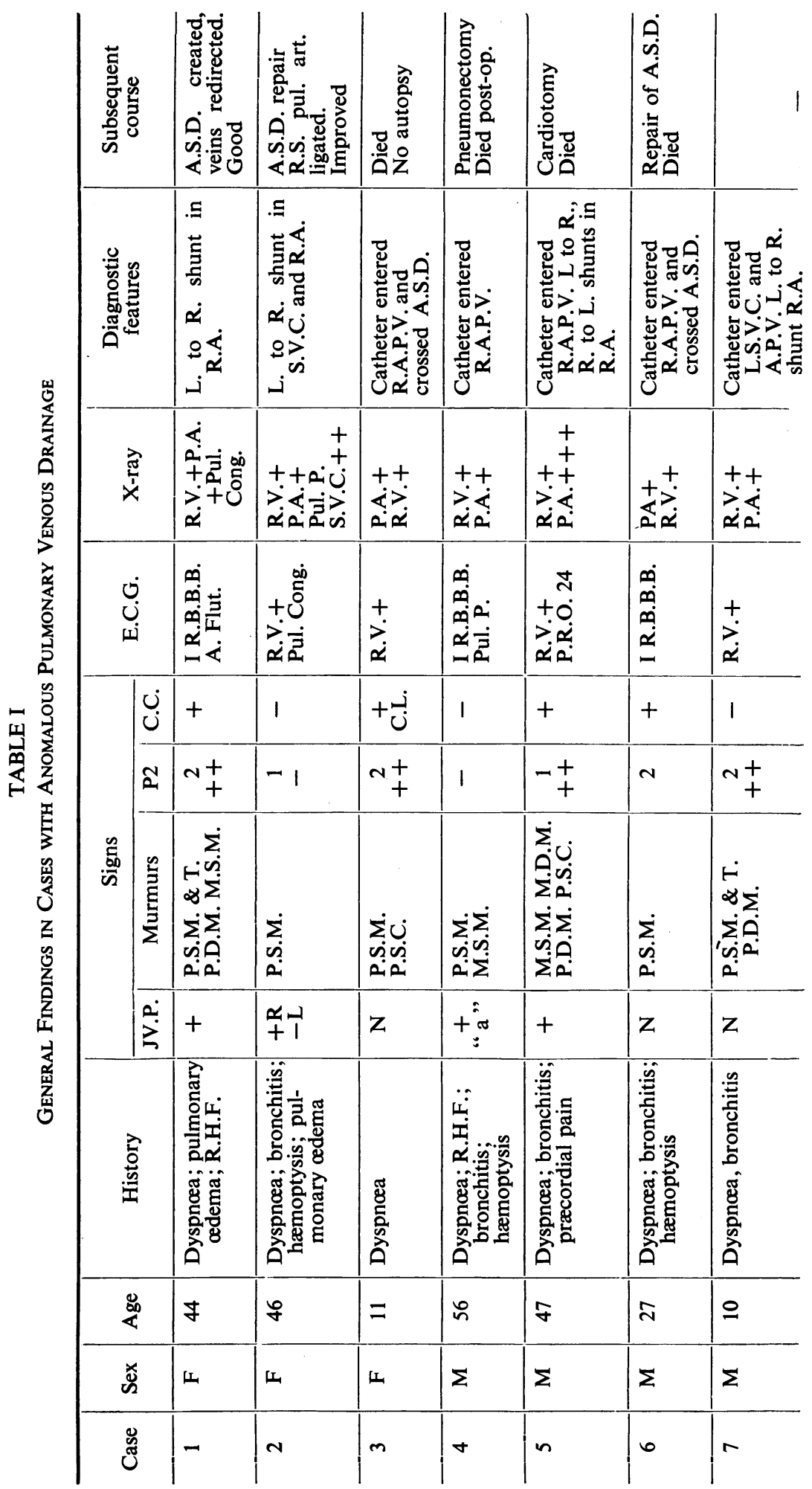




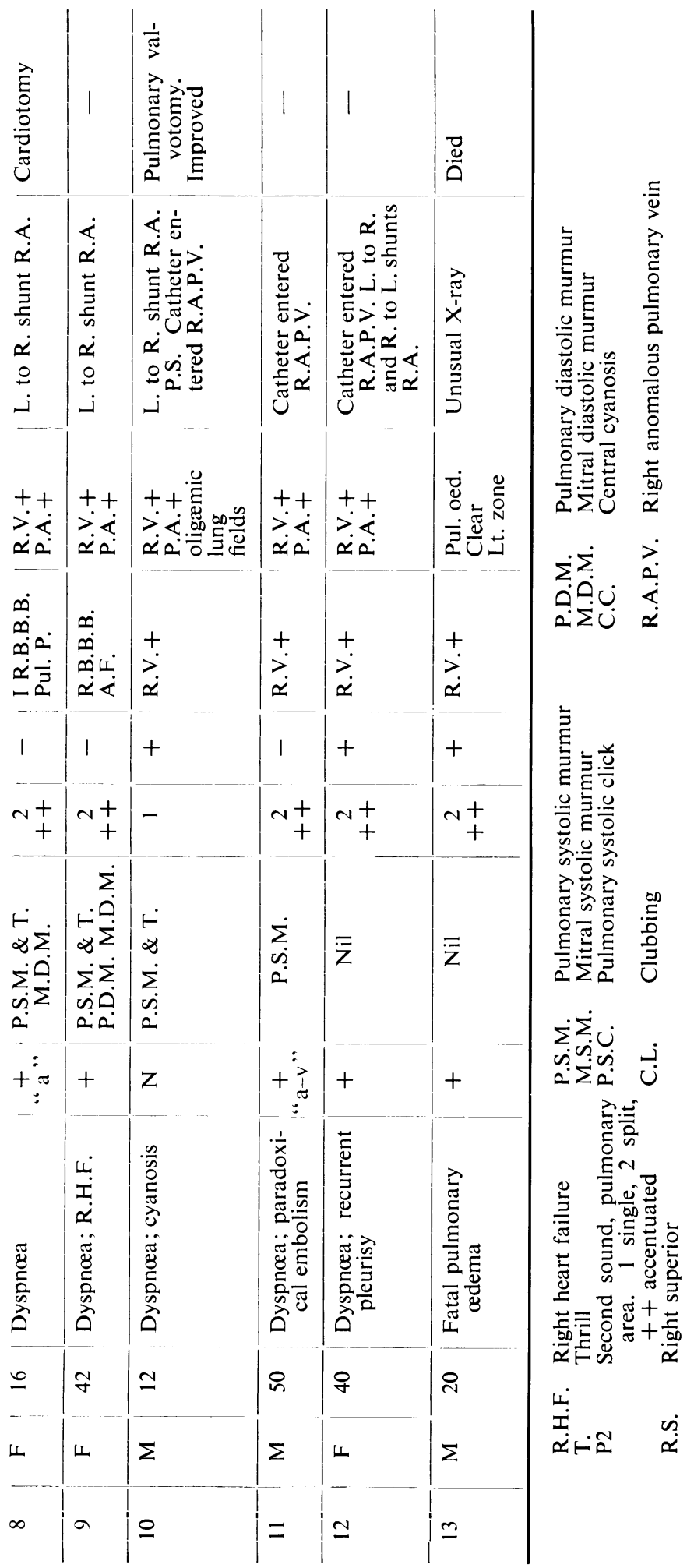




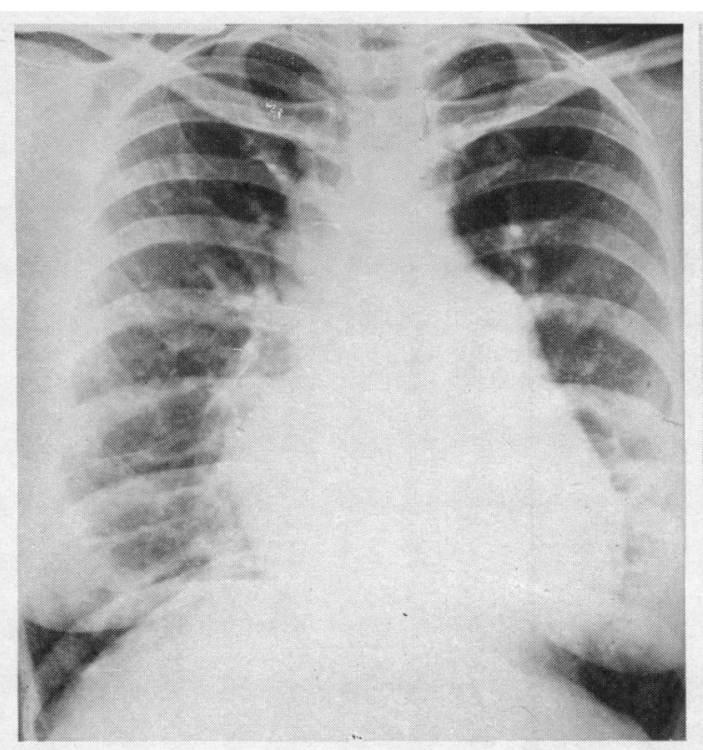

A

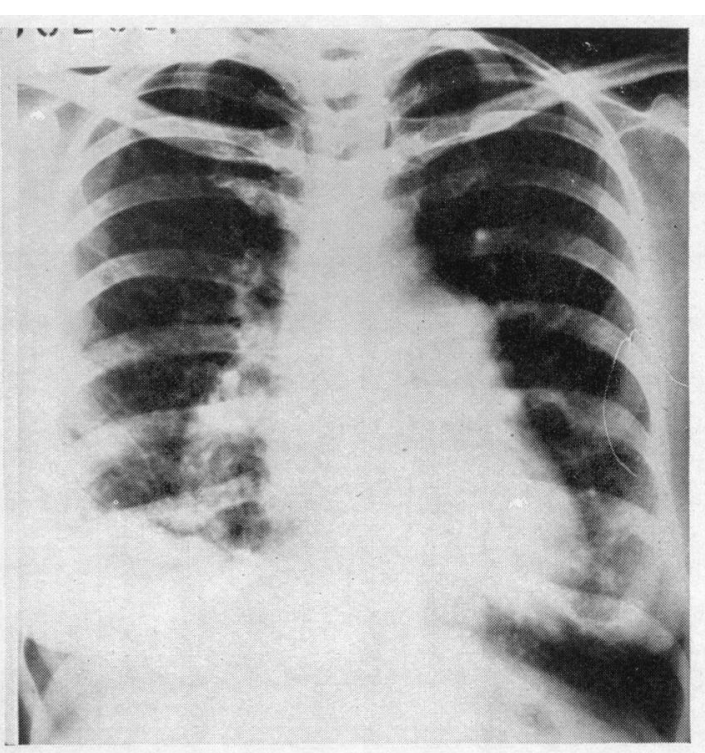

B

FIG. 4.-Aneurysmal superior vena cava before operation (A), and its reduction to normal after operation (B). Case 2.

the importance of the method in the differentiation from uncomplicated atrial septal defect. They also describe a previously unrecognized radiological sign, in the filling defect produced in the atrium, superior vena cava, or left innominate vein at the site of insertion of the anomalous pulmonary vein by the stream of blood from the vein itself deflecting the contrast medium.

All our cases except one (Case 10) showed the radiological picture of increased flow in the pulmonary circuit, and in this instance the anomalous vein was discovered by accident during catheterization. It is important to state that none of our 13 cases was suspected radiologically of having anomalous pulmonary veins although the increased pulmonary flow was clearly visible. Case 13 was unique in that the classical radiological picture of pulmonary œdema was associated with a normal left upper lung zone. The significance of this was not appreciated at the time, but it was later found to be due to anomalous venous drainage of the left upper lobe to a left superior vena cava and right atrium in the presence of mitral stenosis and an intact septum. The anomalous drainage protected this lobe from the general circulatory disturbance (Fig. 5).

\section{CARDiac CATHETERIZation}

It has been pointed out that there is no means of diagnosing the presence of anomalous pulmonary veins clinically, and the diagnosis during life has usually been made at thoracotomy or by means of special investigations; of these, cardiac catheterization is the most informative.

The presence of anomalous pulmonary veins should be considered in all cases of congenital heart disease, and in particular when a diagnosis of atrial septal defect has been made. The discovery of abnormalities of the systemic veins is suggestive. After the catheter has entered the right atrium it may enter a pulmonary vein (Fig. 6 and 7) and then the difficulty arises of being certain whether or not it has first passed through an atrial septal defect. Generally, if the catheter enters a vein from the right lung it is possible to demonstrate without reasonable doubt that the vein is connected to the right atrium by moving the patient under the X-ray screen; the operator can then observe that the catheter has passed straight down the right border of the heart and into the lung without coiling inside the heart shadow (Johnson, 1955; Snellen et al., 1952). If there is doubt, it is helpful to obtain a sample of blood from the vein itself and another on withdrawal as soon as the tip 


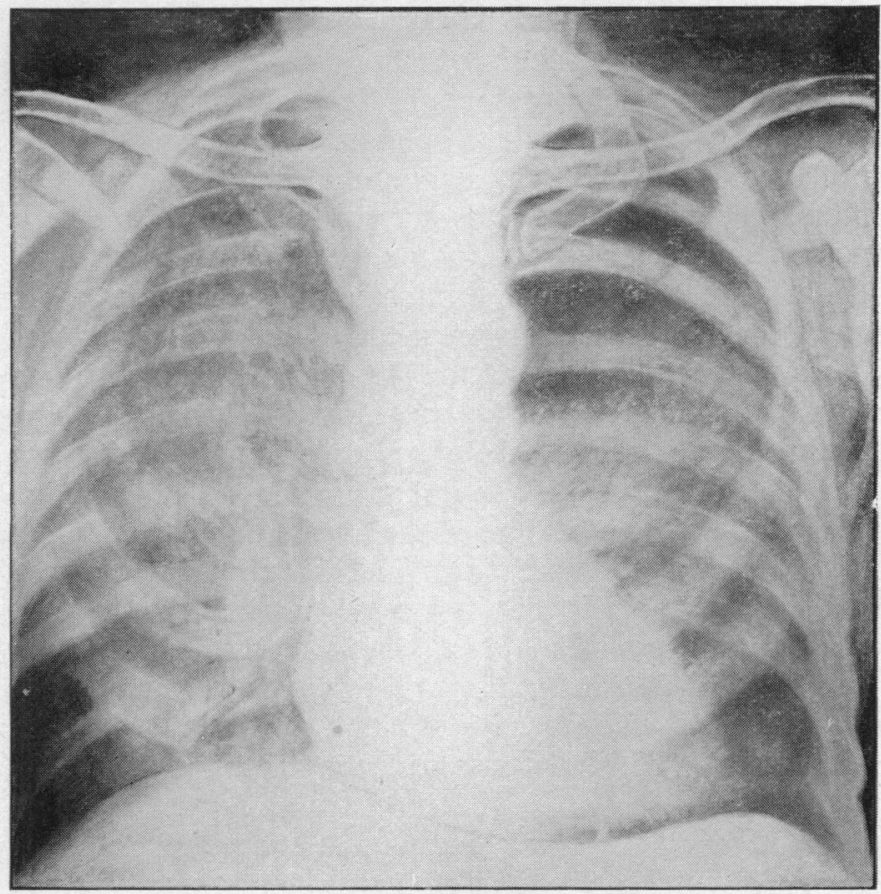

FIG. 5.-Drawing of radiograph of Case 13. Typical picture of pulmonary œdema without involvement of the left upper lobe which had an anomalous venous drainage.

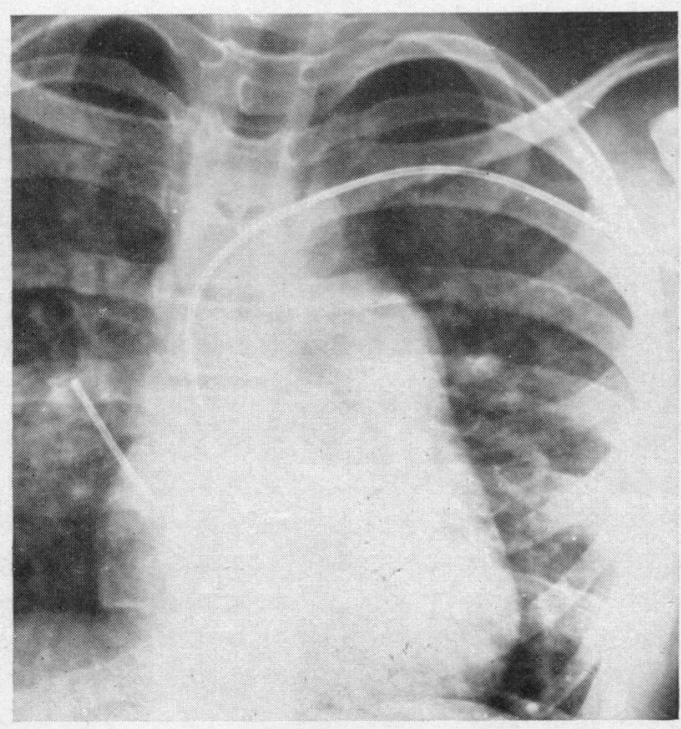

Fig. 6.-Radiograph of Case 3, showing typical appearance of cardiac catheter passing from right atrium into an anomalous right pulmonary vein.

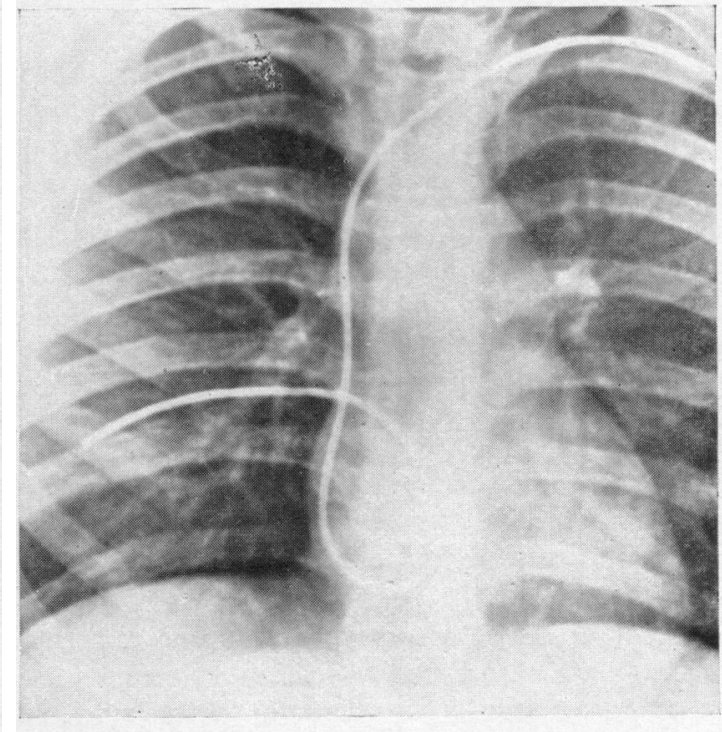

FIG. 7.--Radiograph of Case 10 with cardiac catheter entering an anomalous right pulmonary vein. When this has previously coiled in the right atrium it may be difficult to distinguish from a catheter that has entered a normal pulmonary vein via an atrial septal defect. 
of the catheter leaves the vein and re-enters the cardiac shadow. If the second sample is less saturated than the first, it suggests that the vein in question is entering the right atrium. Dye injection studies are also helpful in this situation (Swan et al., 1953; and Broadbent, 1951; see below).

In all cases where it is likely that anomalous pulmonary veins are present it is important to take at least two samples of blood from the right atrium and one each from the superior and inferior vena cava and an innominate vein, because it is not always possible to demonstrate an anomalous pulmonary vein by passing a catheter into it, and its presence can be inferred when blood samples show evidence of a shunt of oxygenated blood into the right atrium or one of the great veins. If the shunt is demonstrated only in the right atrium it could well be due to an atrial septal defect alone, and in these circumstances dye studies may decide the point (see below).

Calculations of flows and shunts can be attempted by the use of established formulæ, but the results may be invalidated due to the presence of an atrial septal defect. It is difficult to separate the effect of the latter, and also the variation in a shunt from moment to moment with variations in heart rate, respiration, and the oxygen content of the inspired air (Swan et al., 1953).

The results of cardiac catheterization are shown in Table II. All the cases showed evidence of a considerable left-to-right shunt, as might be expected, and a right-to-left shunt was probably present in the eight cases known to have an atrial septal defect. It is noteworthy that the systemic arterial saturation was well below normal in these eight, and in one case with no atrial septal defect (Case 1). The saturation of the pulmonary venous blood was also below normal in three of the five cases in which it was estimated. This contrasts with the findings of other authors (Snellen et al., 1952; Johnson, 1955; and Friedlich et al., 1950) who have found the blood in the anomalous veins to be fully saturated. Pulmonary vascular changes were suspected to be responsible for the low saturation in our cases but unfortunately no histological confirmation was obtained. Significant pulmonary hypertension was present in ten cases and pulmonary stenosis in one : the latter is said to be rare in association with anomalous veins but was present in two of the five cases reported by Sepulveda et al. (1955).

\section{OXIMETRY}

Dye concentration dilution curves were obtained in six patients using T.1824 injected via the cardiac catheter and an ear oximeter (Swan et al., 1953). By this method it was possible to demonstrate a degree of right-to-left shunt at the atrial level in two patients (Cases 5 and 6) and thereby infer that an atrial septal defect was present although the catheter was not passed through it. In both these cases the associated pulmonary venous anomaly was proven by the entry of the catheter into one of the anomalous veins. Later this was confirmed post mortem. In all six a prolonged descending limb of the dye concentration dilution curve indicated a left-to-right shunt. As this effect could be produced both from an atrial defect or from anomalous venous drainage alone or in conjunction with one another it is often difficult to make a firm diagnosis of the presence or absence of such a combined lesion using this technique.

\section{TREATMENT}

The indications for surgical treatment in this condition are the same as those applying to atrial septal defect. A decision that the physician will have to make is whether to confine operative treatment to those with severe disability and thus present the surgeon with poor operative risks, or whether to advise those with high pulmonary blood flow or pulmonary hypertension to submit to an operation that is as yet far from standardized while they themselves are little disabled. Surgical treatment has undergone and is still undergoing changes, and with the increasing safety of operation in the future one may tend to advise it at an earlier date.

The importance of anomalous pulmonary veins was realized many years ago during routine lobectomy and pneumonectomy, and failure to recognize them at operation may be serious or fatal (Healey, 1952; Hwang, 1950). Brantigan (1947) suggested that if there was anomalous drainage of 


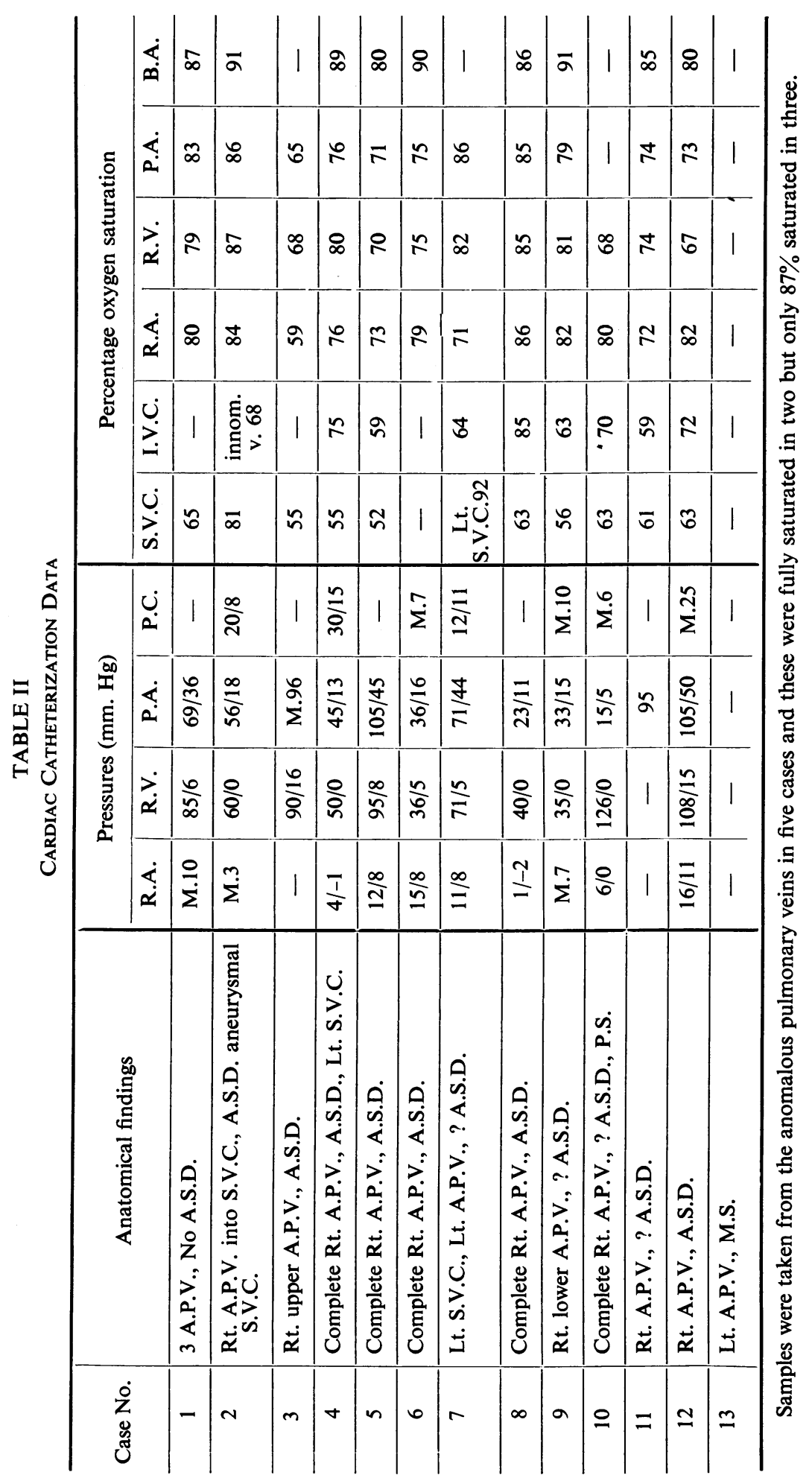


pulmonary blood into the major systemic veins the patient would be benefited by removal of that portion of the lung anomalously drained. In our series pneumonectomy was performed only in Case 4, where the whole of the right lung drained into the right atrium. Unfortunately this patient died of collapse of his remaining lung.

Swan and Mulligan (1948) have demonstrated that a single pulmonary vein can be ligated in the dog and the animal will survive, but that if all the veins from one lung are ligated the result is usually fatal. There is no report of such a procedure in man. In Case 2, ligation of the pulmonary artery to the affected lobe was performed together with closure of an atrial septal defect, and the large pulsating superior vena caval shadow, into which the anomalous pulmonary vein drained, has since disappeared.

Gerbode (1950) showed that large veins could be anastomosed to the left atrium without causing serious disturbance in cardiac function during the procedure, and he pointed out the usefulness of a persistent left superior vena cava for this purpose.

Attempts to correct complete anomalous pulmonary venous drainage have been made in a few cases (Muller, 1951; Snellen and Albers, 1952; Gardner and Oram, 1953; Friedlich et al., 1950; Neptune et al., 1953; and Keith, 1954), but the repair of partial anomalous pulmonary vein drainage, with or without a co-existent atrial septal defect, has been more common (Neptune, 1953; Kirklin, 1953; Johnson, 1955). Bailey (1955) recommends a variety of surgical procedures designed to deal with single and double right anomalous pulmonary vein with and without atrial septal defect, with anomalous left pulmonary veins, and with complete anomalous pulmonary venous drainage. For details the original should be consulted.

\section{SUMMARY}

Thirteen patients with incomplete anomalous pulmonary venous drainage are described. The diagnosis was confirmed at operation or autopsy in nine. Right anomalous pulmonary veins were present in twelve and left anomalous veins in two, an atrial septal defect in nine and possibly two more, a left superior vena cava in three, pulmonary stenosis in one, mitral stenosis in two, and an abnormality of the Eustachian valve in one. The right anomalous veins drained into the superior vena cava or right atrium, and the left veins into a left superior vena cava. The association of right anomalous pulmonary veins and atrial septal defect (usually a posterior one) is common.

The embryology of the pulmonary veins and their association with the atrial septum and the great veins within the chest is discussed.

This anomaly may be complete or incomplete. The complete anomaly was not present in this series but is described. In our patients exertional dyspnœa, recurrent chest injections, hæmoptysis, præcordial pain, and exertional giddiness were the common symptoms. The majority were asymptomatic for many years and cardiac failure when it occurred was rapidly progressive.

The fundamental physiological disturbance is increased pulmonary blood flow which may lead to pulmonary hypertension (10 out of 13). The signs are therefore similar to those found in atrial septal defect. In one patient a unilateral abnormality of the jugular venous pulse was found. In the electrocardiogram 11 patients had normal rhythm, one auricular flutter, one auricular fibrillation, eight right ventricular hypertrophy, four incomplete, and one complete, right bundle-branch block.

Radiologically all patients had cardiac enlargement mainly due to right ventricular hypertrophy and increased prominence of the pulmonary artery and its branches. In one there was an aneurysmal dilatation of the superior vena cava. Figure-of-eight and comma-shaped shadows are mentioned although not present in this series. An unusual radiological picture in a patient with pulmonary œdema is described.

Angiocardiography is informative. Cardiac catheterization was performed in twelve patients and yielded the most useful information. The catheter may enter an anomalous vein or may show evidence of a left-to-right shunt.

Oximetric studies following injection of Evans' blue were performed in six patients, and gave 
useful information in all and diagnostic help in two in whom a degree of right-to-left shunt was present.

The surgical treatment of the condition is reviewed.

The diagnosis of this anomaly requires a variety of procedures because of the difficulties of distinguishing atrial septal defect and anomalous pulmonary veins alone or in combination. It is becoming increasingly important because of its frequency as a chance finding during cardiac catheterization and the need for its recognition before operations for atrial septal defects.

We wish to express our thanks to Dr. R. W. D. Turner for details of Case 12, to Dr. R. Jeremy of Sydney for permission to include Case 13, to Miss J. Dewe for Fig. 8 and to the Department of Medical Photography for the other illustrations. In particular we are grateful to Dr. Raymond Daley for his advice and encouragement, and to Dr. G. de J. Lee for the oximetric investigations.

\section{REFERENCES}

Atkinson, W. J. Jnr., Dean, J. L., Kinnerdell, E. H., and Lambertsen, C. J. (1940). Anat. Rec., 78, 383. Bailey, C. P. (1955). Surgery of the Heart. 1st ed. Henry Kimpton, London.

Barber, J. M., Magidson, C., and Wood, P. (1950). Brit. Heart J., 12, 277.

Bedford, D. E., Papp, C., and Parkinson, J. (1941). Brit. Heart J., 3, 37.

Brantigan, O. (1947). Surg. Gynec. Obstet., 84, 653.

Broadbent, J. C., Clagett, O. T., Burchell, H. S., and Wood, E. H. (1951). Amer. J. Physiol., $167,770$.

Brody, H. (1942). Arch. Path., 33, 221.

Brown, A. J. (1913). Anat. Rec., 7, 299.

Brown, J. W. (1950). Congenital Heart Disease, 2nd ed., Staples Press, London.

Bruce, R., and Hagen, J. (1954). Amer. Heart J., 47, 785.

Bruwer, A. (1953). Proc. Staff Meet. Mayo Clin., 28, 480.

Buell, C. E. (1922). Contributions to Embryology, Carnegie Inst., 14, 11.

Butler, H. (1952). J. Anat., 86, 95.

- (1952). Thorax, 7, 249.

Chun, Chang (1931). Anat. Rec., 50, 1.

Conn, L. C., Calder, J., MacGregor, J. W., and Shaner, R. F. (1942). Anat. Rec., 83, 335.

Davies, F., and MacConaill, M. A. (1937). J. Anat., 71, 437.

Dotter, C. T., Hardisty, N. M., and Steinberg, I. (1949). Amer. J. med. Soc., $218,31$.

Edwards, J. E. (1953). Proc. Staff Meet. Mayo Clin., 28, 441.

- Du Shane, I. W., Alcott, D. L., and Burchell, H. B. (1951). Arch. Path., 51, 446.

Flint, J. M. (1906). Amer. J. Anat., 6, 1.

Friedlich, A. L., Bing, R. J., and Blount, S. G. Jnr. (1950). Bull. Johns Hopkins Hosp., 86, 20.

Gardner, F., and Oram, S. (1953). Brit. Heart J., 15, 305.

Geraci, J. E., and Kirklin, J. H. (1953). Proc. Staff Meet. Mayo Clin., 28, 472.

Gerbode, F., and Hultgren, H. N. (1950). Surgery, 28, 235.

Grishman, A., Pappel, M. A., Simpson, R. S., and Sussman, M. L. (1949). Amer. J. Roentgenol., $62,500$.

Healey, J. E. Jnr. (1952). J. Thorac. Surg., 23, 433.

Hickie, J. B. (1956). Brit. Heart J., 18, 320.

Hughes, C. W., and Runmore, P. C. (1944). Arch. Path., 37, 364.

Hwang, W., Prec., O., Kuramoto, K., Segall, S., and Katz, L. N. (1950). Circulation, $2,553$.

Ingalls, N. W. (1907), Anat. Rec., 1, 14.

Johnson, R. P. (1955). Ann. intern. Med., 42, 11.

Keith, J. D., Rowe, R. D., Vlad, P., and O'Hanley, S. H. (1954). Amer. J. Med., 16, 23.

Kirklin, J. W. (1953). Proc. Staff Meet Mayo Clin., 28, 476.

Knutson, J. R. B., Taylor, B. E., Pruitt, R. D., and Dry, T. J. (1950). Proc. Staff Meet Mayo Clin., $25,52$.

Mankin, H. J., and Burchell, H. B. (1953). Proc. Staff Meet Mayo Clin., 28, 463.

Muller, W. H. (1951). Ann. Surg., 134, 683.

Neptune, W., Bailey, C. P., and Goldberg, H. (1953). J. Thorac. Surg., 25, 623.

Routier, D., Brumlir, J., and Malinsky, A. (1940). Arch. Mal. Cour., 33, 40.

Sepulveda, G., Lukas, D. S., and Steinberg, I. (1955). Amer. J. Med., 18, 883.

Smith, J. C. (1951). Amer. Heart J., 41, 561 .

Snellen, H. A., and Albers, F. H. (1952). Circulation, 6, 801.

Squier, T. L. (1916). Anat. Rec., 10, 425.

Swan, H. J. C., Burchell, H. B., and Wood, E. H. (1953). Proc. Staff Meet. Mayo Clin., 28, 452.

— and Mulligan, R. M. (1948). J. Thorac. Surg., 17, 44.

- and Wood, E. H. (1953). Proc. Staff Meet. Mayo Clin., 28, 95.

Taussig, H. B. (1947). Congenital Malformations of the Heart. The Commonwealth Fund, New York.

Whitaker, W. (1954). Brit. Heart J., 16, 177.

Winslow, J. (1739). Mem. Acad. Roy. Sci., 113.

Wood, P. (1950). Diseases of the Heart and Circulation. Eyre \& Spottiswode, London. 